\title{
Commentary
}

\section{Twice a caesarean, always a caesarean: fact or fiction?}

\author{
P S Wijesinghe ${ }^{1}$, Chanil D Ekanayake ${ }^{2}$ \\ Sri Lanka Journal of Obstetrics and Gynaecology 2012; 34: 131-134
}

\begin{abstract}
In pregnant women with two past caesarean sections where clinical indications for elective delivery are evident an elective repeat caesarean section is warranted. Although some women with two past uterine scars are suitable for a trial of scar, it is not offered due to an over exaggeration of perceived risks and the inability to deal with a failed trial of scar in a society where only the benefits of caesarean section are deep rooted. There is evidence to support that VBAC-2 has a favorable outcome in a subset of carefully selected well informed women.
\end{abstract}

\section{Introduction}

Edward Craigen speaking before the Eastern Medical Society of New York in 1916, pronounced 'once a caesarean, always a caesarean'. However this was at a time when most caesarean sections were classical caesarean sections and although the practice changed to a low transverse caesarean section the notion held sway and took almost half a century for the obstetrician to recognize the feasibility of vaginal birth after a caesarean section (VBAC). Trial of vaginal birth after a previous caesarean section is now an acceptable option ${ }^{1-6}$. However, women wishing a trial of vaginal birth after two caesarean sections (VBAC-2) are generally not allowed to as the subject of VBAC-2 have not received its due consideration among obstetricians. Due to over exaggeration of complications and misinformation regarding efficacy ${ }^{7}$ women requesting such trials are discouraged and may even receive conflicting advice.

\section{The evidence}

In a meta-analysis ${ }^{7}$ of 17 papers involving 5666 patients of VBAC-2, a majority 71.7\% (4064/5666)

\footnotetext{
${ }^{1}$ Professor, ${ }^{2}$ Senior Registrar, Department of Obstetrics and Gynaecology, Faculty of Medicine, Ragama, Sri Lanka.

Correspondence: P S Wijesinghe

E-mail:prasanthaw@gmail.com
}

achieved a vaginal delivery. In a subgroup analysis of VBAC-1 versus VBAC-2; 76.5\% (38 814/50 685) following VBAC-1 and 71.1\% (3276/4565) following VBAC-2 achieved a successful vaginal delivery. Associated uterine rupture rate of $1.59 \%$ versus $0.72 \%$ $(\mathrm{p}<0.001)$ and hysterectomy rate of $0.56 \%$ versus $0.19 \%(p=0.001)$ was observed in VBAC-2 and VBAC1 respectively. Though the absolute figures of complications were low the figures show a difference between the two groups and thus would suggest that if complications were to occur they were likely to be more serious in the VBAC-2 group. Although these figures suggest that VBAC-1 has a better outcome compared to VBAC-2, the more rational and logical comparison would be between VBAC-2 and elective repeat caesarean section (ERCS) as previous surgery would have a higher background risk and the available alternative to women with two CS is an ERCS $^{8}$. Subgroup analysis of VBAC-2 versus ERCS in the meta-analysis by Tahseen ${ }^{7}$ showed comparable hysterectomy $(0.4 \%$ versus $0.63 \%)$, transfusion $(1.68 \%$ versus $1.67 \%)$, postoperative febrile morbidity $(6.03 \%$ versus $6.39 \%)$ and neonatal morbidity $(8.49 \%$ versus $8.85 \%$ ) rates. Outcomes of VBAC-2 have been published over the last two decades and evidence suggests that VBAC-2 has a similar morbidity to ERCS ${ }^{9-25}$.

Cahill et $\mathrm{al}^{26}$ studied the safety and success of vaginal delivery after 3 or more caesarean sections. Although there was measurable maternal morbidity, it did not differ significantly by mode of delivery. This suggests that the morbidity associated in women with two CS may actually be more related to the parity rather than the mode of delivery.

The above studies spanned over a period of more than two decades and the number of women having a trial of labour after two CS varied from $9 \%$ to $69 \%$ in different studies. This indicates the heterogeneous nature of the study populations. Furthermore there is also the possibility of over-representation of favorable results in the published literature. However it is obvious that, avoidance of major abdominal surgery, shorter hospital stay ${ }^{5}$ with early mobilization, reduced risk of thromboembolic events in the postpartum period $^{27}$, and reduced risk of morbidly adherent placenta in subsequent pregnancies, are advantageous to the mother when delivered vaginally ${ }^{5}$. 
The benefits to the newborn include lesser risk of respiratory problems as the incidence of persistent pulmonary hypertension was found to be almost fivefold higher in those delivered by caesarean section $^{28}$. A large population based cohort study done in Norway showed that children delivered by caesarean section had a $52 \%$ increased risk of asthma compared with vaginally delivered children (adjusted hazard ratio $[\mathrm{HR}]=1.52 ; 95 \%$ confidence interval $[\mathrm{CI}]$ $=1.42-1.62$ ). A stronger association was observed in those delivered by elective CS compared to emergency CS with 59\% $(\mathrm{HR}=1.59 ; 95 \% \mathrm{CI}=1.44-1.75)$ and $42 \%$ $(\mathrm{HR}=1.42 ; 95 \% \mathrm{CI}=1.25-1.61)$ risk respectively ${ }^{29}$. These findings may have important implications when obtaining consent prior to an elective caesarean section in future.

However a subgroup analysis of VBAC-2 versus ERCS revealed rates of perinatal death or asphyxial injury as $0.09 \%$ with VBAC-2 versus $0.01 \%$ with ERCS $(\mathrm{P}=0.14)^{7}$, although the difference may not reach statistical significance it may be clinically important. It must also be borne in mind that the data is about one to two decades old and hence the neonatal morbidity figures may not be representative of current practice given the considerable advances in neonatal care in recent years.

\section{The circumstances}

In some women with two previous scars an elective caesarean section is inevitable; these situations include a weak scar, a recurrent indication, an obstetric problem or a scenario where a safe vaginal delivery is not feasible. The strength of the scar would be of pivotal concern as it is related to the risk of uterine rupture. A weak scar may be due to an incision other than a low transverse incision such as an upper vertical, low vertical, inverted $\mathrm{T}$ or a $\mathrm{J}$, which will render the uterus more prone to rupture ${ }^{6}$. In addition to this another factor which will affect the strength of the scar is the quality of its repair. Though one may suggest that the strength of the scar would be poorer in women with single layer closure there is no evidence to support this contention. In fact evidence from a retrospective study showed that there was no difference in the rate of uterine rupture in women who had a single layer closure as opposed to a double layer closure $^{30}$. Recurrent indications such as contracted pelvis or uterine anomaly would render a vaginal delivery unsafe as would a patient with a medical complication which necessitates early delivery such as preeclampsia. In women with abnormal placentation the decision is obvious as vaginal delivery is not feasible.

Macones ${ }^{20,}$ Phelan $^{23}$ and Hansell ${ }^{17}$ noted better prospects for successful VBAC-2 in women with a previous vaginal birth, as for VBAC-1 where women who had a prior vaginal birth in addition to one prior caesarean delivery were more likely to have a successful VBAC attempt compared with women without a prior vaginal birth. Macones et $\mathrm{al}^{20}$ also concluded that the majority of ruptures occurred in women either induced or augmented and in those who had not had a previous vaginal delivery. Thus it would seem reasonable to target VBAC-2 attempts in those with a previous vaginal delivery and avoid induction or augmentation to reduce the risk of rupture. The American College of Obstetricians and Gynecologists' recommendation too is that for women with two prior caesarean deliveries, only those with a prior vaginal delivery should be considered for a trial of scar ${ }^{5}$. Our personal experience too suggests that VBAC-2 in women with a history of previous vaginal delivery who go into spontaneous labour have a favorable maternal and fetal outcome. These women without an indication for an ERCS were carefully evaluated with regard to the quality of scar and cephalo-pelvic disproportion before embarking on a VBAC-2. Although febrile morbidity has significantly reduced after the advent of broad spectrum antibiotics ${ }^{7}$, concern regarding postoperative infectious morbidity continues to be a major concern as genital tract sepsis has become the leading cause of direct maternal death in the UK for the first time since these Confidential Enquiries into Maternal Deaths commenced in $1952^{31}$. This is a cause for concern, particularly as it has occurred against a background of an overall decrease in maternal mortality.

\section{Sri Lankan setting}

Women with two previous caesarean sections almost always undergo an ERCS in the next pregnancy in most centres in Sri Lanka. One of the misconceived reasons is that sterilization is required after the third operative delivery. While the contention is obviously wrong, higher failure rate of postpartum sterilization, subsequent maternal regret and request for reversal are factors against this practice. This argument is conveniently forgotten when one or more previous babies are not living. Other instances are in women with two previous scars when presented with a late second trimester miscarriage or an intrauterine death where all measures including oxytocin and even prostaglandins are experimented with in order to achieve a vaginal birth.

There are unique problems in a developing country such as Sri Lanka as most caesarean sections are done by junior staff at varying levels of training with limited resources in an overburdened health care system. More often than not the degree of difficulty is not assessed which would result in immediate complications and implications for future pregnancies. The possibility of adhesions and morbidly adherent 
placenta would render an elective repeat caesarean section more hazardous in such a setting due to higher blood loss, possibility of blood transfusion, visceral damage, wound infection necessitating multidisciplinary care, more intensive post operative monitoring, postoperative antibiotics and a longer hospital stay. With such a backdrop of potential problems one may question the safety of an ERCS.

The Society of Obstetricians and Gynaecologists of Canada recommends that informed consent with appropriate documentation should be an important part in the management of patients with previous caesarean sections ${ }^{4}$. This is another area of concern as informed written consent is either taken for granted or improperly obtained. The reasons for this are that most patients are ignorant of their rights, lack of knowledge about relevant evidence among staff, and they are either too busy or not properly trained to obtain informed consent.

Vaginal birth after a previous caesarean section necessitates intensive monitoring of the labouring mother and the fetus ${ }^{6}$. This is an area of concern as health care resources are stretched and most units would be incapable of providing such care at all times. This is probably the perceived reason for ERCS in most units. Available evidence suggests that VBAC1 in Sri Lanka is almost as safe as a VBAC1 in a developed country ${ }^{32}$. This emphasizes the importance of clinical judgment and careful patient selection as it would compensate for the limitation in resources which will have a bearing on the safety of VBAC2 as well.

\section{The challenges and limitations}

There are many obstacles to overcome when attempting VBAC-2. One main challenge is that there is no reliable prospective method to judge the quality of the scar which is the pivotal factor that determines the risk of uterine rupture. Therefore we are forced to review past notes to assess the type of uterine incision. However due to inadequate documentation this may be falsely reassuring. Assessment of the quality of the repair too suffers from the same insult. Continuous electronic fetal monitoring is recommended during a VBAC but this could be offset by careful patient selection and accurate clinical evaluation during labour. However whether this is practically feasible in our setting is debatable. Another dilemma arises when some women though favourable for a VBAC-2 do not go in to spontaneous labour ${ }^{6}$. In a misinformed society where only the benefits of caesarean section are deep rooted it can be challenging to deal with a failed VBAC. Though measures are in place for emergency caesarean section it may be practically difficult to attend to category I/II caesarean sections in an under-resourced setting.

\section{Conclusion}

In a pregnant woman with two past caesarean sections; a weak scar, a recurrent indication, an obstetric complication in the current pregnancy or a scenario where a safe vaginal delivery is not feasible an ERCS is indicated. It is now well established that a trial of scar is an acceptable safe option in women with one previous caesarean section. There is evidence to suggest that VBAC-2 has similar morbidity compared to elective repeat caesarean section. In a subset of carefully selected well informed pregnant women with two uterine scars a good outcome can be expected if a trial of scar is offered following spontaneous onset of labour. The available evidence suggests that those with a history of past vaginal delivery have an even better chance of a successful VBAC-2.

\section{References}

1. Rosen MG, Dickinson JC, Westhoff CL. Vaginal birth after caesarean: a meta-analysis of morbidity and mortality. Obstet Gynecol 1991; 77(3): 465-70.

2. Flamm BL, Newman LA, Thomas SJ, Fallon D, Yoshida MM. Vaginal birth after cesarean delivery: results of a 5-year multicenter collaborative study. Obstet Gynecol 1990; 76: 750-4.

3. Rossi CA, D'Addario V. Maternal morbidity following a trial of labour after caesarean section vs elective repeat caesarean delivert; a systematic review with meta-analysis. Am J Obstet Gynecol 2008; 199(3): 224-31.

4. Society of Obstetricians and Gynaecologists of Canada (SOGC). SOGC clinical practice guidelines. Guidelines for vaginal birth after previous caesarean birth. Number 155 (Replaces guideline Number 147) Int J Gynaecol Obstet 2005; 89(3): 19-31.

5. American College of Obstetricians and Gynaecologists Practice bulletin (July 2004) Vaginal birth after previous cesarean delivery clinical management guidelines for Obstetrician-Gynecologists No 54.

6. Royal College of Obstetricians and Gynaecologists. Green top guideline No. 45. (February 2007). Birth after previous caesarean birth.

7. Tahseen S, Griffiths M. Vaginal birth after two caesarean sections (VBAC-2) - a systematic review with meta-analysis of success rate and adverse outcomes of VBAC-2 versus VBAC-1 and repeat (third) caesarean sections. BJOG 2010; 117(1):5-19.

8. Mesleh RA, Al Naim M, Krimly A. Pregnancy outcome of patients with previous four or more caesarean sections. J Obstet Gynaecol 2001; 21(4): 355-7.

9. Asakura H, Myers SA. More than one previous caesarean delivery: a 5-year experience with 435 patients. Obstet Gynecol 1995; 85(6): 924-9. 
10. Boabang P, Bogesits-Aufschneider R, Hug K. [Vaginal delivery after two previous cesarean sections]. (in German) Zentralbl Gynakol 1999; 121(9): 449-53.

11. Bretelle F, Cravello L, Shojai R, Roger V, D'ercole C, Blanc $B$. Vaginal birth following two previous cesarean sections. Eur J Obstet Gynecol Reprod Biol 2001; 94(1): 23-6.

12. Chattopadhyay SK, Sherbeeni MM, Anokute CC. Planned vaginal delivery after two previous caesarean sections. $\mathrm{Br} \mathrm{J}$ Obstet Gynaecol 1994; 101(6): 498-500.

13. Farmakides G, Duvivier R, Schulman H. Vaginal birth after two or more previous caesarean sections. Am J Obstet Gynecol 1987; 156(3): 565-6.

14. Garg VK, Ekuma-Nkama EN. Vaginal birth following two cesarean deliveries - are the risks exaggerated? Ann Saudi Med 2004; 24(4): 276-9.

15. Granovsky-Grisarau S, Shaya M, Diamant YZ. The management of labor in women with more than one uterine scar: is a repeat caesarean delivery really the only safe solution? J Perinat Med 1994; 22(1): 13-7.

16. Guettier X, Marpeau L, Larue L, Jault T, Rhimi Z, Barrat J. [A uterus with two scars: can we allow vaginal delivery?] (in French) J Gynecol Obstet Biol Reprod 1992; 21(1): 103-7.

17. Hansell RS, McMurray KB, Huey GR. Vaginal birth after two or more cesarean sections: a five-year experience. Birth 1990; 17: 146-50.

18. Jamelle RN. Outcome of unplanned vaginal deliveries after two previous caesarean sections. J Obstet Gynaecol Res 1996; 22(5): 431-6.

19. Landon MB, Spong CY, Thom E, Hauth JE, Bloom SL, Varner MW, et al. Risk of uterine rupture with a trial of labor in women with multiple and single prior cesarean delivery. Obstet Gynecol 2006; 108(1): 12-20.

20. Macones GA, Cahill A, Pare E, Stamilio DM, Ratcliffe S, Stevens E, et al. Obstetric outcomes in women with two prior cesarean deliveries: is vaginal birth after cesarean delivery a viable option? Am J Obstet Gynecol 2005; 192(4): 1223-8.

21. Miller D, Diaz D, Paul R. Vaginal birth after ceaserean; a 10 year experience. Obstet Gynecol 1994; 84(2): 155-6.
22. Novas J, Myers SA, Gleicher N. Obstetric outcome of patients with more than one previous caesarean section. Am JObstet Gynecol 1989; 160(2): 364-7.

23. Phelan JP, Ahn MO, Diaz F, Brar HS, Rodriguez MH. Twice a caesarean, always a caesarean? Obstet Gynecol 1989; 73(2): 161-5.

24. Porreco RP, Meier PR. Trials of labor on patients with multiple previous cesarean sections. J Reprod Med 1983; 28(11): 770-2.

25. Pruett KM, Kirshton B, Cotton DB. Is vaginal birth after two or more caesarean sections safe? Obstet Gynecol 1988; 72(2): 163-5.

26. Cahill A, Tuuli M, Odibo A, Stamilio D, Macones G. Vaginal birth after caesarean for women with three or more prior caesareans: assessing safety and success. BJOG 2010; 117(4): 422-8.

27. Royal College of Obstetricians and Gynaecologists. Green top guideline No. 37a. (November 2009). Reducing the risk of thrombosis and embolism during pregnancy and the puerperium.

28. Levine E, Ghai V, Barton J, Storm C. Mode of delivery and risk of respiratory diseases in newborns. Obstet Gynecol 2001; 97(3): 439-42.

29. Tollanes MC, Moster D, Daltveit AK, Irgens LM. Cesarean section and risk of severe childhood asthma: A population -based cohort study. J Pediatr 2008; 153(1): 112-6.

30. Durnwald C, Mercer B. Uterine rupture. Peri-operative and perinatal morbidity after single layer and double layer closure at caesarean delivery. Am J Obstet Gynecol 2003; 189(4): 925-9.

31. Centre for Maternal and Child Enquiries (CMACE). Saving Mothers' Lives: reviewing maternal deaths to make motherhood safer: 2006-08. The Eighth Report on Confidential Enquiries into Maternal Deaths in the United Kingdom. BJOG 2011; 118(Suppl. 1): 1-203.

32. Ranaweera A, Rishard M, Kalansooriya H, Priyantha G, Madurika D, Ibrahim. Vaginal delivery after caesarean section in a limited resource setting: A Sri Lankan experience. Proceedings of 44th annual scientific sessions; 2011 April 22-25; Colombo, Sri Lanka. Sri Lanka Journal of Obstetrics and Gynaecology 2011; 33: 73. 